\title{
Post SPD Material's Recovery in Thermal Exposition
}

\author{
T. KVAČKAJ*, A. KováČOvÁ And R. KOČIŠKO \\ Technical University of Košice, Faculty of Metallurgy, Department of Metal Forming, \\ Letná 9, 04200 Košice, Slovakia
}

\begin{abstract}
The mechanical and thermo-physical properties of $\mathrm{Cu}-\mathrm{Cr}-\mathrm{Zr}$ alloys in dependence on processing conditions were studied. The processing conditions consisted of solution annealing at temperature of $1020^{\circ} \mathrm{C}$ for 60 min followed by water quenching. This was followed by one equal channel angular pressing pass carried out at ambient temperature, ageing treatment $\left(T_{\mathrm{AT}} \in\left(20 ; 480{ }^{\circ} \mathrm{C}, t_{\mathrm{AT}} \in\langle 30 ; 150\rangle \min \right)\right.$ and cooling in water. The maximal strengthening effect coming from dislocations \& grain size refinement \& precipitation strengthening of $\Delta \mathrm{HV} 0.1=130$ was achieved at $T_{\mathrm{AT}}=480^{\circ} \mathrm{C}$ and for $t_{\mathrm{AT}}=120 \mathrm{~min}$. From differential scanning calorimetry analysis, two partial exothermal peaks were recognized and classified as major and minor, these peaks are used to determination the stored energy coming from recrystallization and precipitation $\left(\Delta H_{R}\right.$ and $\left.\Delta H_{P}\right)$. The maximal value in stored energy of $H_{1 \times \mathrm{ECAP}}=2.923 \mathrm{~J} / \mathrm{g}$ was obtained after 1 st ECAP pass.
\end{abstract}

DOI: 10.12693 /APhysPolA.128.689

PACS: 81.05.Bx, 81.07.-b, 81.20.Hy, 81.40.Cd

\section{Introduction}

The $\mathrm{Cu}-\mathrm{Cr}-\mathrm{Zr}$ alloy is classified as a precipitationhardened $(\mathrm{PH})$ material processed by heat treatment. Typical heat treatment is based on solution annealing at high temperatures followed by water quenching (WQ) in order to create a supersaturated solid solution and ageing. The ageing process produces fine precipitates of the second phase with a precipitation hardening effect. Such alloy provides high mechanical properties, high heat resistance, high electrical and thermal conductivity [1]. The mechanical properties of PH alloys depend strongly on the following strengthening mechanisms: grain refinement (up to a nanoscale level), precipitation hardening through the presence of second phase particles, dislocation hardening, solid solution and the Peierls-Nabarro hardening. Nowadays, equal-channel angular pressing (ECAP) is a method based on severe plastic deformation (SPD) which has been successfully used for reducing the grain size diameter and to increase the dislocation density resulting in greater mechanical properties [2-4]. The post-processing after ECAP through the ageing process (temperature vs. time conditions) has an impact on final mechanical properties by the effect of precipitation hardening $[5,6]$.

To obtain the precipitation hardening effect there is necessary to apply the solution annealing (SA) followed by WQ in order to dissolve the second phase particles in the solid solution. Further ECAP processing leads to the structural refinement and together with combination of the post ECAP ageing to the precipitation strengthening which finally has an impact on the mechanical properties increase. The effect of precipitation strengthening depends on the amount of $\mathrm{Cr}$ and $\mathrm{Zr}$ content that can be in

*corresponding author; e-mail: tibor.kvackaj@tuke.sk the range of $\mathrm{Cr} \in\langle 0.4 ; 1.5\rangle$ wt $\%$ and $\mathrm{Zr} \in\langle 0.03 ; 0.5\rangle$ wt $\%$. Authors [7] have mentioned that the $\mathrm{Zr}$ content can also be reduced to $0.1 \mathrm{wt} \%$ or less. According to the authors [8], an average solubility of the concentration for chromium is $\mathrm{Cr}_{\text {solubility }} \approx 0.4 \mathrm{wt} \%$ at $1000^{\circ} \mathrm{C}$ on the other hand when temperature falls down at $400^{\circ} \mathrm{C}$, an average solubility of the concentration is dramatically changed to $\mathrm{Cr}_{\text {solubility }} \approx 0.03 \mathrm{wt} \%$. Since low content of $\mathrm{Cr}$ provides the coarse $\mathrm{Cr}$ precipitates forming, tendency is to obtain the $\mathrm{Cr}$ content below upper limit. Considering precipitation processes, in literature there are a lot experimental studies mostly carried out under the following conditions: $T_{\mathrm{SA}} \in(950 ; 970\rangle^{\circ} \mathrm{C}, t_{\mathrm{SA}} \in\langle 0.3 ; 3\rangle \mathrm{h} \& \mathrm{WQ}$ followed by cold rolling or tensile testing with subsequent ageing treatment at $T_{\mathrm{AT}} \in\langle 400 ; 525\rangle{ }^{\circ} \mathrm{C}, t_{\mathrm{AT}} \in\langle 0 ; 20\rangle \mathrm{h}[9-14]$. In these studies, there have been not documented presence of any intermetallic chromium or zirconium phases in the microstructure, only presence of $\mathrm{Cr}$ precipitates together with coarse $\mathrm{Cu}_{5} \mathrm{Zr}$ or $\mathrm{Cu}_{3} \mathrm{Zr}$ in its surrounding embedded into a pure $\mathrm{Cu}$ matrix. The precipitation temperature was determined at $T \approx 370{ }^{\circ} \mathrm{C}$ and $\mathrm{Cr}$ $T \approx 425^{\circ} \mathrm{C}$ for $\mathrm{Cu}_{5} \mathrm{Zr}$ or $\mathrm{Cu}_{3} \mathrm{Zr}$ and $\mathrm{Cr}$ (with a diameter of 1-50 nm), respectively. Hence, according to the literature overview, there is necessary to perform additional experimental studies.

In the present work, experimental findings involving mechanical properties in the $\mathrm{Cu}-\mathrm{Cr}-\mathrm{Zr}$ alloy processed by ECAP and post ECAP annealing are presented. Special attention is focused on the study of thermal changes in materials processed under different ageing conditions.

\section{Experimental conditions}

As an experimental material, $\mathrm{Cu}-\mathrm{Cr}-\mathrm{Zr}$ alloy in a cylindrical bar $\left(D \times L=10 \times 100 \mathrm{~mm}^{2}\right)$ with chemical composition of $98.54 \mathrm{wt} \% \mathrm{Cu}, 1.1 \mathrm{wt} \% \mathrm{Cr}, 0.043 \mathrm{wt} \% \mathrm{Zr}$ and $0.317 \mathrm{wt} \%$ impurities was used. Before ECAP, samples were heat treated under the following conditions: 
$T_{\mathrm{SA}}=1020^{\circ} \mathrm{C}, t_{\mathrm{SA}}=1 \mathrm{~h} \& \mathrm{WQ}$. The samples were processed once through an ECAP die (channel angle $\Phi=90^{\circ}, \Psi=32^{\circ}$ and the diameter of $10 \mathrm{~mm}$ ) at ambient temperature, with route $\mathrm{Bc}$.

After ECAP and heat treatment processing, samples were subjected to thermal DSC measurements carried out by STA 449 F1 Jupiter apparatus in the temperature range of $T_{\mathrm{DSC}} \in\langle 40 ; 700\rangle^{\circ} \mathrm{C}$ with a heating rate $30^{\circ} \mathrm{C} / \mathrm{min}$. From DSC analysis, stored energy as the area below final DSC curves was calculated. Each sample was subjected to two measurements, the curve from the second one was used as a baseline to obtain the higher precision. The samples after one ECAP pass were aged under the following conditions: $T_{\mathrm{AT}} \in(20 ; 480\rangle^{\circ} \mathrm{C}$, $t_{\mathrm{AT}} \in\langle 30 ; 150\rangle$ min followed by cooling in water. Microhardness measurements HV0.1 (after ageing) were done using the Struers apparatus.

\section{Results and discussion}

\subsection{Microhardness}

The results from microhardness measurements are given in Fig. 1. The microhardness after SA\& WQ was HV0.1 $1_{\mathrm{SA}}=50$. Figure $1 \mathrm{a}, \mathrm{b}$ shows changes in microhardness in the experimental material as a function of ageing temperature and ageing time. According to Fig. 1a, microhardness was growing with the temperature increase. Moreover, there is seen that up to $200{ }^{\circ} \mathrm{C}$ microhardness was growing slightly, but then the rapid increase was recognized. Ageing time plays also a significant role in the microhardness increase, even ageing time and ageing temperature are influenced by each other strongly.

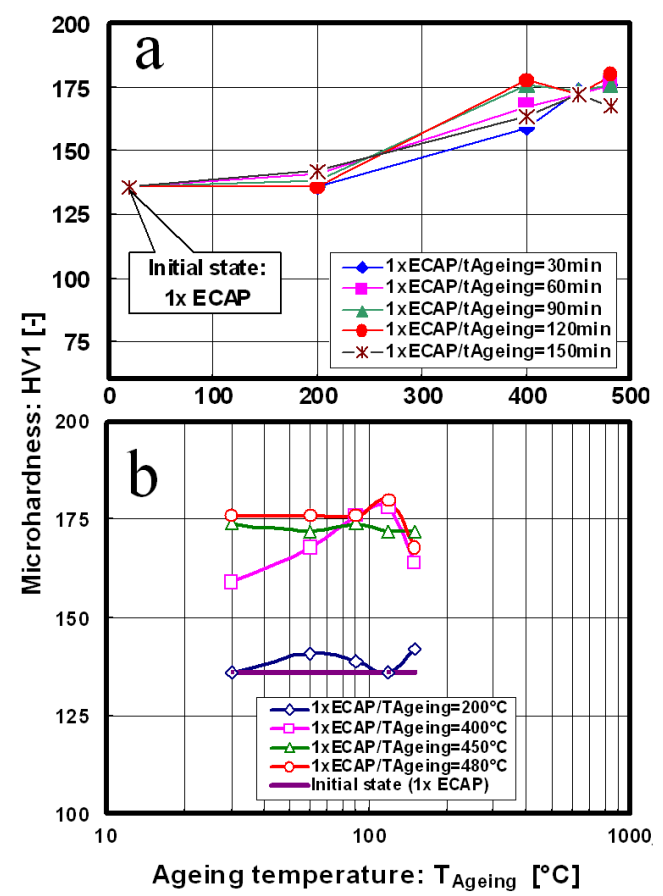

Fig. 1. Microhardness in dependence on: a) ageing temperature and $b$ ) ageing time.
Maximum microhardness HV0.1 $1_{1 \times \mathrm{ECAP}+\mathrm{AT}}$ of 180 was obtained after the following ageing treatment processing: $T_{\mathrm{AT}}=480^{\circ} \mathrm{C}$ and $t_{\mathrm{AT}}=120 \mathrm{~min}$. Moreover, under $T_{\mathrm{AT}}=400^{\circ} \mathrm{C}$ and $t_{\mathrm{AT}}=120 \mathrm{~min}$ processing, there was also achieved high microhardness: HV0.1 $1 \times \mathrm{ECAP}+\mathrm{AT}=$ 178. According to the analysis, there is highly expected that a maximal strengthening effect was from the increment in a dislocations portion and grain refinement: $\Delta \mathrm{HV} 0.1=\mathrm{HV} 0.1_{1 \times \mathrm{ECAP}+\mathrm{AT}}-\mathrm{HV} 0.1_{\mathrm{SA}}=180-50=$ 130. According to the previous literature overview focused on studies of the precipitation, it is possible to suppose that post ECAP ageing leads to the formation of fine $\mathrm{Cr}$ precipitates together with coarse $\mathrm{Cu}_{5} \mathrm{Zr}$ or $\mathrm{Cu}_{3} \mathrm{Zr}$ in its surrounding embedded into a pure $\mathrm{Cu}$ matrix.

\section{2. $D S C$ calorimetry}

Figure 2 provides the example of heat flux during DSC measurements and Fig. 3 provides DSC findings which are schematically illustrated. From the graphical dependences, there was recognized an endothermal peak followed by two local exothermal peaks on DSC curves for both states (without ECAP and 1xECAP). According to the authors [15], endothermal peaks can be attributed to the dissolution of solute clusters which are being formed in dislocation walls at low temperatures. First peak of the exothermal reaction is recognized in the interval of $T_{\text {peak }} 1 \in\langle 282 ; 284\rangle^{\circ} \mathrm{C}$ and $T_{\text {onset } 1} \in$ $\langle 258 ; 267\rangle^{\circ} \mathrm{C}$, second one is recognized in the interval $T_{\text {peak } 2} \in\langle 494 ; 530.3\rangle^{\circ} \mathrm{C}$ and $T_{\text {onset } 2} \in\langle 435 ; 449\rangle^{\circ} \mathrm{C}$. Next emerging exothermal peaks can be associated to the annihilation of defects and the precipitation of secondary particles during a recovery process [16]. The first exothermal peak is associated to $\mathrm{Cu}_{3} \mathrm{Zr}$ or $\mathrm{Cu}_{5} \mathrm{Zr}$ precipitates and second exothermal peak is associated to $\mathrm{Cr}$ particles [14]. As was mentioned above, Fig. 3 schematically illustrates findings from DSC measurements, values of the first peak are slightly affected by ECAP true strain. Next, with the ECAP true strain rising, values of the second exothermal peak are shifting to the low

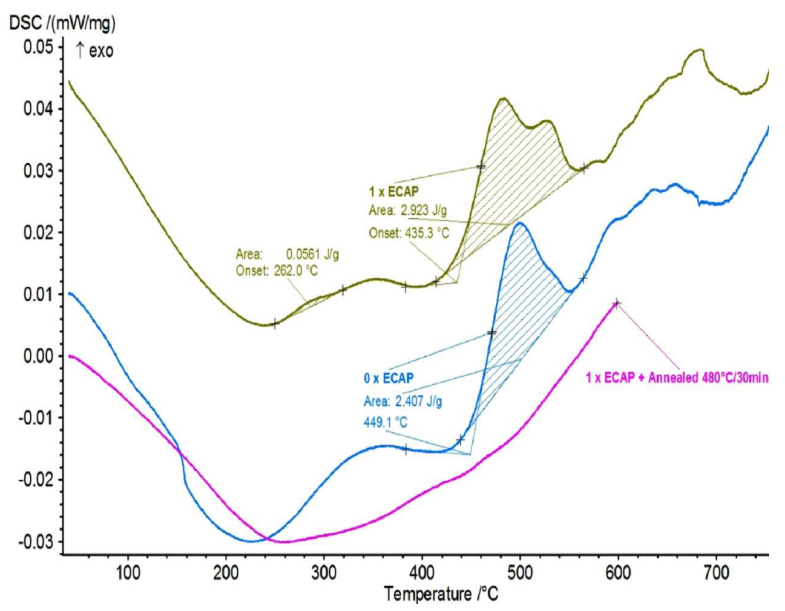

Fig. 2. Heat flux after post ECAP heating. 


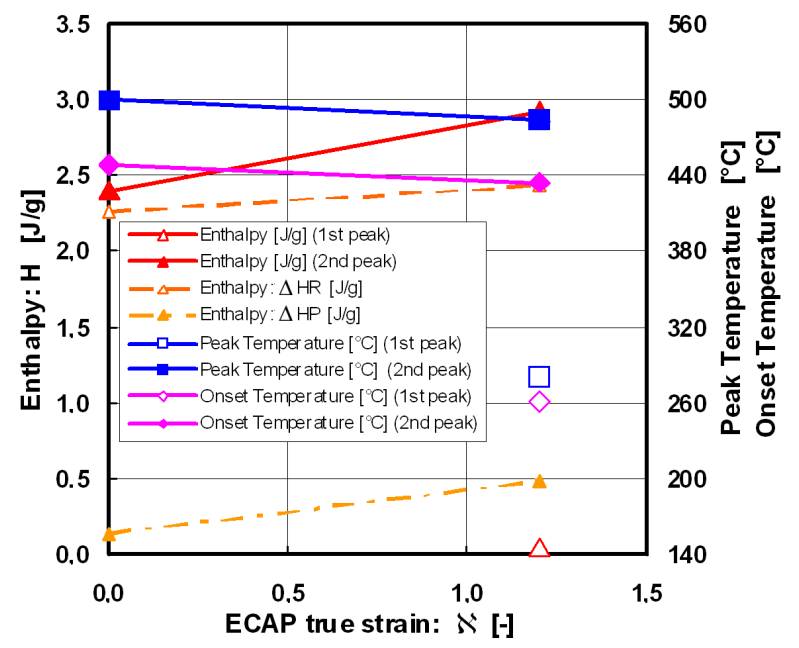

Fig. 3. DSC analysis.

temperatures. The onset temperature for these exothermal reactions including all ECAP true strains can be described by the following formula:

$T_{\text {onset_1 }}=0.24 T_{\text {melting }}, T_{\text {onset_2 }}=0.4 T_{\text {melting }}$.

It is well known that stored energy from the atoms accumulation could be defined as the enthalpy and hence there is possible to express the storage energy through enthalpy. The dislocation's forming and moving process throughout the samples subjected to cold ECAP led to the increase in stored energy and subsequent strengthening (greater microhardness). The maximal increment in microhardness coming from the 1st ECAP was $56 \mathrm{HV} 0.1 / \varphi=1$. Figure 3 also presents the changes in stored energy in dependence on true ECAP strains. The 1st exothermal peaks had not such significant influence on stored energy $\left(\Delta H_{\max }=0.069 \mathrm{~J} / \mathrm{g}\right)$. On the other hand, for the 2 nd peaks $\left(\Delta H_{\max }=1.65 \mathrm{~J} / \mathrm{g}\right)$, strong exothermal reactions were observed. Every 2nd exothermal reaction is described by two partial peaks (major and minor) which are used to determine the stored energy for major and minor peaks $\left(\Delta H_{R}\right.$ and $\left.\Delta H_{P}\right)$, respectively. Total stored energy is given as a sum of partial stored energies

$$
H=H_{R}+H_{P}(J / g) \text {. }
$$

According to the previous evaluation in strengthening increment, partial stored energies can be defined as follows: $H_{R}$ - stored energy from work hardening or the releasing process given as a recovery or recrystallization and $H_{P}$ - stored energy from precipitation. Based on Fig. 3, stored energy was maximal at the value of $H_{1 \times \mathrm{ECAP}}=$ $2.923 \mathrm{~J} / \mathrm{g}$ after 1 st $\operatorname{ECAP}$ pass $(\varphi=1.2)$. The 1 st ECAP pass causes the following increment in stored energy: $T_{\text {peak_2, } 1 \times \text { ECAP }}=484.3^{\circ} \mathrm{C}: \Delta H_{0-1 x E C A P}=H_{1 \times \mathrm{ECAP}}-$ $H_{0 \times \mathrm{ECAP}}=2.923-2.409=0.514 \mathrm{~J} / \mathrm{g}$ which is attributed to the work hardening increment as follows: $\Delta H_{0-1, R}=$ $H_{R, 1 \times E C A P}-H_{R, 0 \times E C A P}=2.44-2.27=0.17 \mathrm{~J} / \mathrm{g}$ and to the precipitation strengthening increment as follows: $\Delta H_{0-1, P}=H_{P, 1 \times E C A P}-H_{P, 0 \times E C A P}=0.483-0.139=$
$0.344 \mathrm{~J} / \mathrm{g}\left(\Delta H_{0-1 \times E C A P}=\Delta H_{0-1, R}+\Delta H_{0-1, P}=\right.$ $0.17+0.344=0.514 \mathrm{~J} / \mathrm{g})$.

From calculations, the difference in contributions coming from recrystallization and precipitation could be described as follows: $\Delta H_{0-1, R}<\Delta H_{0-1, P}$ which implies greater strengthening contribution coming from precipitation than from work hardening. The increment in stored energy after 1 st ECAP pass at $T_{\text {peak }} 2,1 \times$ ECAP $=$ $484.3^{\circ} \mathrm{C}$ was confirmed by the previous experiment which was aimed to the study of strength properties affected by different ageing conditions, where the maximal value of hardness was obtained at $T_{\mathrm{AT}}=480^{\circ} \mathrm{C}$. What is concerning of the main mechanisms and behavior of metals and alloys during processing by ECAP was discussed by authors [17].

\section{Conclusions}

In the present study, there is used the ECAP method and heat treatment to enhance the strength properties in $\mathrm{Cu}-\mathrm{Cr}-\mathrm{Zr}$ with subsequent analysis through DSC and microhardness measurements.

According to this study, the following conclusions can be made:

- maximal microhardness value $\mathrm{HV} 0.1_{1 \times \mathrm{ECAP}+\mathrm{AT}}=$ 180 is obtained under the following conditions: $T_{\mathrm{AT}}=480^{\circ} \mathrm{C}$ and $t_{\mathrm{AT}}=120 \mathrm{~min}$;

- according to the DSC analysis, one initial endothermal peak followed by two local exothermal peaks were recognized;

- each 2nd exothermal reaction is described by two partial peaks (major and minor) which are used to determine the stored energy for major and minor peaks $\left(\Delta H_{R}\right.$ and $\left.\Delta H_{P}\right)$, respectively;

- stored energy was maximal at the value of $H_{1 \times \mathrm{ECAP}}=2.923 \mathrm{~J} / \mathrm{g}$ after 1 st ECAP pass $(\varphi=1.2)$.

\section{Acknowledgments}

This work was financially supported by the VEGA $1 / 0325 / 14$ project.

\section{References}

[1] A.A.F. Tavassoli, J. Nucl. Mater. 258-263, 85 (1998).

[2] R. Pernis, J. Kasala, J. Bořuta, Kovove Mater. 48 , 41 (2010).

[3] R. Pernis, J. Kasala, J. Bořuta, Acta Metal. Slov. 15, 5 (2009).

[4] R. Bidulsky, J. Bidulska, M. Actis Grande, High Temp. Mater. Process. 28, 337 (2009).

[5] R. Kocisko, R. Bidulsky, L. Dragosek, M. Skrobian, Acta Metal. Slov. 20, 302 (2014). 
[6] M. Matvija, M. Fujda, O. Milkovic, T. Kvackaj, M. Vojtko, P. Zubko, R. Kocisko, Acta Metal. Slov. 18, 4 (2012).

[7] D.L. Ellis, B.A. Lerch, Increased Mechanical Properties through the Addition of $Z r$ to GRCop-84, NASA Technical Reports, 2012.

[8] H. Fuxiang, M. Jusheng, N. Honglong, G. Zhiting, L. Chao, G. Shumei, Y. Xuetao, W. Tao, L. Hong, L. Huafen, Scr. Mater. 48, 97 (2003).

[9] V.R. Barabash, G.M. Kalinin, S.A. Fabritsiev, S.J. Zinkle, J. Nucl. Mater. 417, 904 (2011).

[10] M. Hatakeyama, T. Toyama, Y. Nagai, M. Hasegawa, M. Eldrup, B.N. Singh, Mater. Trans. 49, 518 (2008).

[11] U. Holzwarth, M. Pisoni, R. Scholz, H. Stamm, A.J. Volcan, J. Nucl. Mater. 279, 19 (2000).
[12] Z. Mei, L. Guobiao, W. Zidong, Z. Maokui, China Foundry 5, 268 (2008).

[13] Z. Pan, J. Chen, W. Zhou, J. Li, Mater. Trans. 54, 1403 (2013).

[14] H. Suzuki, M. Kanno, J. Jpn. Inst. Met. Mater. 36, 363 (1972).

[15] M. Verdier, I. Groma, L. Flandin, J. Lendvai, Y. Bréchet, P. Guyot, Scr. Mater. 37, 449 (1997).

[16] X.F. Li, A.P. Dong, L.T. Wang, Z. Yu, L. Meng, J. Alloys Comp. 509, 4670 (2011).

[17] R.Z. Valiev, T.G. Langdon, Progr. Mater. Sci. 51, 881 (2006). 